\title{
Motion Graphic Rate Card TVC Batam TV
}

\author{
Nur Imma Aulia Astori', Sandi Prasetyaningsih ${ }^{2}$ \\ ${ }_{1,2}^{1,2}$ oliteknik Negeri Batam, Batam, Indonesia \\ ** Multimedia and Network Engineering, Batam State Polytechnic (9 pt)
}

\begin{tabular}{|c|c|}
\hline Article Info & ABSTRACT \\
\hline & \multirow{13}{*}{$\begin{array}{l}\text { PT. Batam Multimedia Televisi (Batam TV) merupakan stasiun televsi lokal } \\
\text { yang berdiri pada tanggal } 17 \text { Januari } 2003 \text { dan Batam TV termasuk kedalam } \\
\text { Group Jawa Pos Multimedia (JPM) sebagai stasiun televisi lokal pertama yang } \\
\text { ada di Kepulauan Riau. Implementasi Motion Graphic Rate Card TVC Batam } \\
\text { Tv, bertujuan untuk memberikan informasi dengan kemasan yang menarik } \\
\text { kepada masyarakat mengenai tarif harga untuk pemasangan iklan di Batam Tv. } \\
\text { Informasi yang akan di sampaikan mencakup semua tarif harga mulai dari hari, } \\
\text { jam dan waktunya.Motion graphic pada video promosi ini dibuat } \\
\text { menggunakan metode pengembangan dan validasi suatu produk yaitu Villamil } \\
\text { - Molina. Setelah produk selesai dibuat, tahap berikutanya yaitu menganalisa } \\
\text { tingkat pengaruh dan efektifitas media promosi dalam bentuk motion graphic } \\
\text { dengan menggunakan EPIC Model.Hasil analisis menggunakan parameter } \\
\text { EPIC Model, yakni dimensi Empathy, Persuation, Impact dan } \\
\text { Communocation. Dari hasil analisis dan perhitungan menggunakan parameter } \\
\text { EPIC Model dengan persentase EPIC RATE yaitu 4.46 didapatkan bahwa } \\
\text { video promosi ini efektif dan layak untuk dipublikasikan dan dibagikan kepada } \\
\text { konsumen Batam Tv. }\end{array}$} \\
\hline Received Okt $15^{\text {th }}, 2021$ & \\
\hline Revised Nov $12^{\text {th }}, 2021$ & \\
\hline Accepted Des $23^{\text {th }}, 2021$ & \\
\hline & \\
\hline Keyword: & \\
\hline Batam Tv & \\
\hline Motion Graphic & \\
\hline EPIC Model & \\
\hline & \\
\hline & \\
\hline & \\
\hline & \\
\hline
\end{tabular}

\section{INTRODUCTION (10 PT)}

Pada era sekarang ini media promosi pada suatu perusahaan adalah kebutuhan yang paling berpengaruh dan sangat penting bagi siklus ekonomi suatu perusahhan [1]. Ada berbagai bentuk promosi dalam menyampaikan informasi, salah satu bentuk promosi yang sering digunakan sebagai media promosi adalah motion graphic. Motion graphic adalah grafis yang menggunakan video atau bentuk animasi untuk menciptakan suatu gerak dan transformasi sehingga informasi yang ditampilkan akan dipahami oleh masyarakat. Salah satu media yang punya pengaruh besar dimasyarakat adalah televisi. Saat melihat televisi berbagai tayangan akan disajikan seperti iklan, baik iklan masyarakat maupun iklan comersil. iklan adalah bentuk penyajian ide atau mempromosikan suatu barang dan jasa yang memerlukan biaya sebagai siklus pendapatan dari suatu instansi terkait [2].

PT. Batam Multimedia Televisi merupakan stasiun televisi lokal yang berdiri pada tanggal

17 Januari 2003 dan stasiun televisi lokal pertama yang ada di Kepulauan Riau. Salah satu sumber penghasilan media elektronik maupun media cetak adalah iklan comersil ataupun media cetak comersil. Setiap media pastinya

mempunyai standar harga untuk memasang sebuah iklan comersil atau yang biasa di sebut

rate card dalam pemasangan iklan, begitu juga dengan PT. Batam Multimedia Televisi [3]. Awalnya PT. Batam Multimedia Televisi mempunyai rate card berbentuk media cetak yang diberikan kepada konsumen yang akan memasang iklan di Batam TV. Seiring

perkembangan zaman yang semakin canggih maka Batam TV membutuhkan pembaharuan rate card agar lebih mudah dalam memasarkannya kepada konsumen. Bedasarkan permasalahan tersebut, penelitian ini akan mencoba membahas permasalahan tersebut dengan melakukan penelitian dengan judul "Motion Graphic Rate Card TVC Batam TV" dan akan dilanjutkan dengan menganalisa efektifitas video promosi dengan menggunakan metode EPIC Model. 


\section{RESEARCH METHOD (10 PT)}

Membuatan video dilakukan dengan menggunakan tahapan metode Villamil-Molina yang dapat dilihat pada Gambar 1.

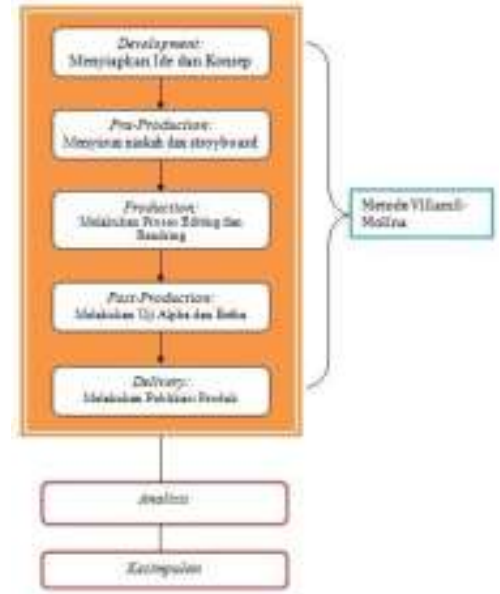

Gambar 1 Tahapan Villamil-Molina

Pembuatan video Motion Graphic bebagai media promosi ini menggunakan metode Villamil - Molina [7]. Metode Villamil - Molina memiliki tahapan - tahapan pengembangan multimedia seperti development, preproduction, production, post production, delivery. Dalam proses development dilakukan penentuan konsep video dan warna dan dalam tahap Pre-Production, akan dilakukan penentuan asset, narasi, storyboard, audio, rancangan kuisioner, dan rancangan analisis. Pada tahap Production dilakukan proses tracing, animating, editing, dan rendering. Pada tahap Post production dilakukan proses analisis dan kesimpulan, dan pada tahap delivery akan dilakukan proses publikasi.

\subsection{Pengembangan (Development)}

Tahap pengembangan (development) dilakukan untuk mendifinisikan tujuan dan tahapan awal pembuatan produk dan juga menentukan dan mengembangan ide dan konsep dari produk. Adapun video motion graphic yang akan dibuat ialah video rate card Batam TV. Video ini ditujukan kepada masyarakat Batam dari semua kalangan yang belum mengetahui mengenai standar harga pemasangan iklan di Batam TV. Video ini nantinya berisi kumpulan animasi-animasi yang dibuat menjadi motion dan menjelasakan tentang tarif pemasangan iklan di jam-jam tertentu dan hari-hari tertentu.

\subsection{Pre-Production}

Tahap ini merupakan tahapan awal pada pembuatan produk yakni pembuatan storyboard dan scripwriting. Contoh bentuk story board dapat di lihat pada table 1. 
Tabel 1 Contoh bentuk storyboard

\begin{tabular}{|c|c|c|}
\hline No & Gambar & Keterangan \\
\hline 1 & $\begin{array}{ll}x \\
0 \\
\end{array}$ & $\begin{array}{l}\text { Terdapat objek } \\
\text { TV dan peta } \\
\text { kota batam } \\
\text { yang } \\
\text { menujukan } \\
\text { sejarah singkat } \\
\text { Batam TV. } \\
\text { Framing : } \\
\text { Normal Angle, } \\
\text { Medium Close } \\
\text { Up } \\
\text { Musik : mbb } \\
\text { ocean no } \\
\text { copyright }\end{array}$ \\
\hline 2 & 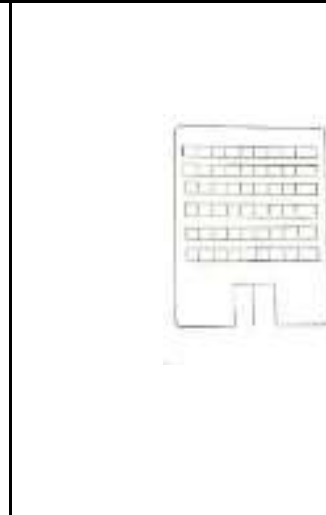 & $\begin{array}{l}\text { Menunjukan } \\
\text { gedung graha } \\
\text { pena dan } \\
\text { menjelaskan } \\
\text { sejarah singkat } \\
\text { berdirinya } \\
\text { Batam TV. } \\
\text { Framing : } \\
\text { Normal Angle } \\
\text { Musik : mbb } \\
\text { ocean no } \\
\text { copyright }\end{array}$ \\
\hline
\end{tabular}

Tahap selanjutnya adalah membuat scriptwriting. Contoh scriptwriting dapat di lihat pada table 2.

Tabel 2 Contoh Sripwriting

\begin{tabular}{|c|c|c|c|}
\hline Scene & Deskrips & Audio & Narasi \\
\hline \multicolumn{4}{|c|}{ Scene 1 - Sejarah } \\
\hline Visual & $\begin{array}{l}\text { Muncul } \\
\text { penjelasa } \\
\text { n dan } \\
\text { sejarah } \\
\text { singkat } \\
\text { Batam } \\
\text { TV }\end{array}$ & $\begin{array}{l}\text { Backs } \\
\text { ound } \\
\text { dan } \\
\text { Voice }\end{array}$ & $\begin{array}{l}\text { PT. Batam } \\
\text { Multimedi } \\
\text { a Televisi atau } \\
\text { Batam TV merupakan televisi } \\
\text { lokal pertama di Batam } \\
\text { Kepulauan Riau. Berdiri Sejak } \\
\text { tanggal } 17 \\
\text { Januari } \\
2003 \text {. }\end{array}$ \\
\hline
\end{tabular}




\begin{tabular}{|l|l|l|l|}
\hline Scene & Deskripsi & Audio & Narasi \\
\hline Scene 2 - Sejarah \\
\hline Visual & Muncul & Back & Tersebar di \\
& penjelas & soun & Batam, \\
& an & dan & Bintan, \\
& cakupan & Voice & $\begin{array}{l}\text { Tanjung } \\
\text { pinang dan }\end{array}$ \\
& Batam & & Karimun \\
\hline
\end{tabular}

\subsubsection{Produksi}

Proses yang dilakukan pada tahap ini adalah melakukan tracing dari sketsa yang sudah kita buat pada tahap sebelumnya ini termasuk kedalam produksi dikarenakan pada tahap sebelumnya hanyalah dalam bentuk blue print saja, pengembangan animasi dari desain grafis yang sudah dibuat, pemilihan audio, editing dan rendering video hingga menjadi sebuah produk jadi yaitu motion graphic yang di implementasikan sebagai media promosi.

\subsubsection{Post-Production}

Pada tahap ini akan dilakukan pengujian untuk mengetahui kelayakan produk yang dibuat. Rancangan kuisoner dapat lihat pada tabel 3.

Tabel 3. Rancangan Kuisoner

\begin{tabular}{|c|c|c|}
\hline No & Aspek & Dimensi \\
\hline $\mathrm{P} 1$ & $\begin{array}{l}\text { Apakah video ii } \\
\text { menyampaikan } \\
\text { informasi yang } \\
\text { menarik }\end{array}$ & Emphaty \\
\hline $\mathrm{P} 2$ & $\begin{array}{l}\text { Apakah video ini } \\
\text { memberikan keyakinan } \\
\text { kepada anda atas } \\
\text { informasi yang } \\
\text { diberikan }\end{array}$ & Persuation \\
\hline P3 & 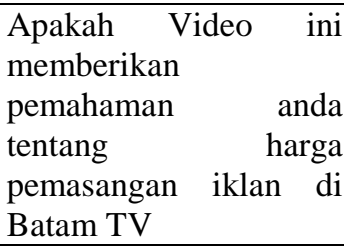 & Impact \\
\hline $\mathrm{P} 4$ & $\begin{array}{lr}\text { Video } & \text { ini } \\
\text { menyampaikan } & \text { pesan } \\
\text { dengan jelas } & \end{array}$ & Communication \\
\hline
\end{tabular}

Pengujian dilakukan dalam bentuk pemberian kuisioner dengan menggunakan parameter EPIC Model. Untuk bagian analisis, data di analisis dengan menggunakan skor rata-rata berbobot yaitu setiap jawaban responden diberikan bobot. Cara menghitung skor adalah menjumlahkan seluruh hasil kali nilai masing-masing bobotnya dibagi dengan jumlah total frekuensi. Rumus menghitung skor rata-rata terbobot :

$\mathrm{X}=$ Rata - rata bobot

$\mathrm{Fi}=$ Frekuensi

$\mathrm{Wi}=$ bobot nilai

$$
\mathrm{X}=\frac{\sum f i w i}{\sum f i}
$$

Langkah selanjutnya adalah menggunakan rentang skala yang terbentuk dari Teknik skala peringkat dengan menggunakan skala antara 1 hingga 5 yang menggambarkan posisi sangat tidak setuju ke posisi yang sangat setuju. Didapatkan hasil rentang skala sebesar 0,8 dari perhitungan (bobot terbesar - bobot terkecil) / banyak kategori bobot. Hasil tersebut digunakan dalam rentang digunakan ke dalam rentang skala keputusan sebagai bahan pengambilan keputusan dari hasil analisis EPIC Model pada tabel 4.

Tabel 4 Rentan Skala

\begin{tabular}{|c|c|}
\hline Kriteria & Rentan Skala \\
\hline Sangat Tidak Efektif & $1,00-1,80$ \\
\hline Tidak Efektif & $1,81-2,60$ \\
\hline Cukup Efektif & $2,61-3,40$ \\
\hline
\end{tabular}




\begin{tabular}{|c|c|}
\hline Efektif & $3,41-4,20$ \\
\hline Sangat Efektif & $4,21-5,00$ \\
\hline
\end{tabular}

Langkah terakhir adalah menentukan nilai EPIC Rate lalu di cocokan ke rentang skala untuk mengetahui nilai kriteria dari setiap parameter EPIC model yang akan menentukan efektif tidaknya produk motion graphic ini .

\subsubsection{Delivery}

Tahap delivery merupakan proses terakhir, yang dilakukan pada tahap ini adalah pengemasan produk dan publikasi ke media online Batam TV yaitu Instagram. Aspek ratio yang digunakan yaitu 1:1 dikarenakan fokus dari promosi video ini hanya melalui media sosial instagram saja

\section{RESULTS AND ANALYSIS (10 PT)}

Dalam bagian ini akan dijelaskan tentang Hasil dan Analisa, Pada bagian hasil merupakan proses Production yang akan meliputi tentang tracing, animating, editing, dan rendering.

\subsection{Implementasi}

\subsubsection{Tracing}

Proses ini dilakukan untuk semua sketsa yang telah di buat, dan akan menjadi hasil akhir, Dimana ini masuk dalam tahap produksi dikarenakan pada tahap praproduksi hanya lah gambar yang bersifat blue print dan masih berbentuk coretan pensil.

Tabel 5 Hasil gambar

\begin{tabular}{|l|c|}
\hline & (a) \\
\hline & \\
\hline
\end{tabular}

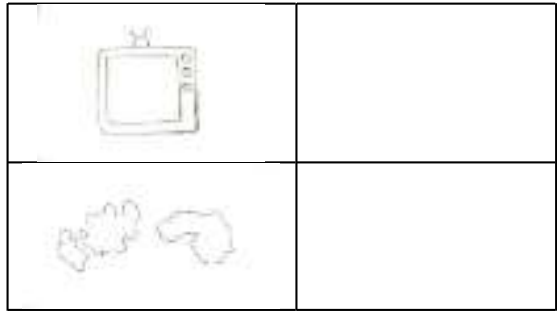

\subsubsection{Animating}

Setelah Proses tracing semua hasil di masukan ke dalam Adobe After Effect untuk dilakukan proses animating. Proses animating memberikan animasi yang sesuai kepada asset di dalam tiap-tiap scene nya digabungkan dengan text dari narasi dari tiap scene dan disesuaikan dengan storyboard. Dimana Teknik yang digunakan yaitu seamless transition dimana Teknik motion graphic yang mengandalkan transisi pada tiap konten / scene pada video

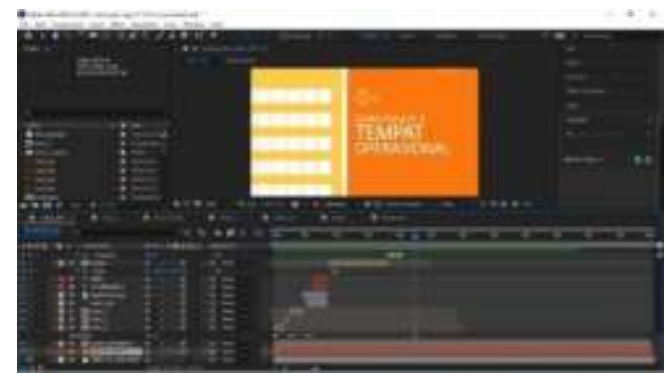

\subsubsection{Dubbing}

Pada tahap ini, yang dilakukan adalah merekam suara untuk membantu menjelaskan isi dari video yang dibuat agar semakin mudah dimengerti penjelasan- penjelasan yang ada pada video rate card ini. Pada proses dubbing ini menggunakan Adobe Audition CS6 sebagai software untuk melakukan editing, sedangkan hardware yang digunakan yaitu menggunakan microphone dan mixer untuk merekam hasil dubbing. 


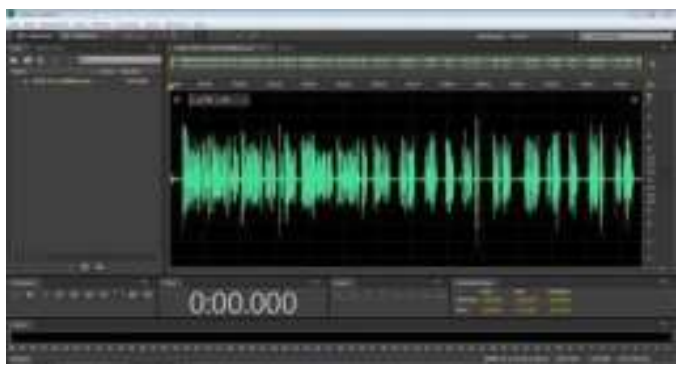

\subsubsection{Editing}

Gambar 3 Proses dubbing

Setelah selesai tahapan dubbing, selanjutnya yang dilakukan adalah editing. Pada tahap ini yang dilakukan adalah menggabungkan audio dan animasi yang sudah dibuat menjadi sebuah video. Software yang digunakan ditahap ini adalah Adobe Premier Pro CS6. Proses editing bisa dilihat pada gambar 4 .

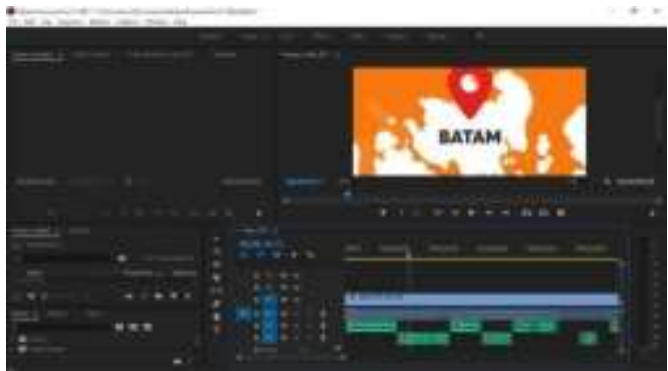

Gambar 4 Proses editing

\subsubsection{Rendering}

Pada tahap ini merupakan tahap terakhir dari proses produksi, yaitu rendering. Rendering dilakukan setelah tahap editing selesai, lalu akan dilakukan render dengan menggunakan software yang sama yaitu Adobe Premiere Pro CS6. Proses rendering bisa dilihat pada gambar 5.

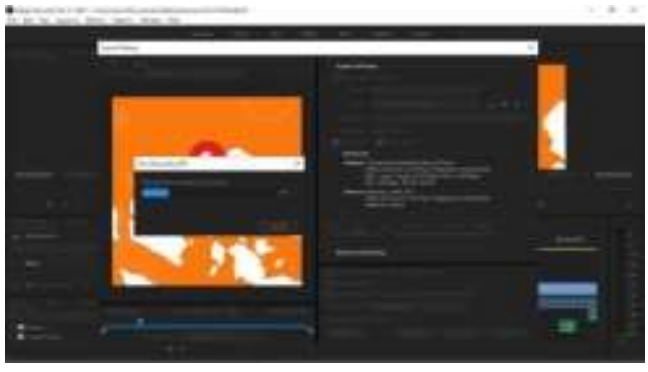

Gambar 5 Proses rendering

\subsection{Analisis}

Analisis dilakukan dengan cara menyebar quisioner kepada client Batam TV dan maskarakat umum yang berjumlah 30 orang, data quisioner yang didapatkan ada pada tabel 6. dan pada penjelasan dibawah ini

\section{a. Empathy}

Terdapat 2 butir pernyataan yang menjadi tolak ukur untuk dimensi empathy pada tugas akhir ini yaitu :

\section{Butir Pertanyaan X1}

dapat diketahui bahwa sebanyak 63,3\% yang memilih sangat setuju, 36\% yang memilih setuju, dan tidak ada yang memilih kurang Setuju, tidak setuju dan sangat tidak setuju. Dari data pada tabel 4.4 dapat disimpulkan bahwa responden setuju jika video promosi yang ditampilkan menarik.

\section{Butir Pertanyaan X2}

dapat diketahui bahwa sebanyak 46,6\%yang memilih sangat setuju, 50\% yang memilih setuju, 2,4\% yang memilih kurang Setuju dan tidak ada, tidak setuju dan sangat tidak setuju. Dari data pada tabel 4.5 dapat disimpulkan bahwa responden setuju jika video promosi yang ditampilkan mudah dipahami. 


\section{b. Persuation}

Terdapat 2 butir pernyataan yang menjadi tolak ukur untuk dimensi persuation pada penelitian ini yaitu : Butir Pertanyaan X3

dapat diketahui bahwa sebanyak 46,6\% yang memilih sangat setuju, 53\% yang memilih setuju, dan tidak ada yang memilih kurang Setuju, tidak setuju dan sangat tidak setuju. Dari data pada tabel 4.6 dapat disimpulkan bahwa responden setuju jika video promosi yang ditampilkan memberikan keyakinan.

\section{Butir Pertanyaan X4}

dapat diketahui bahwa sebanyak 43,3\% yang memilih sangat setuju, 53\% yang memilih setuju, 2,4\% yang memilih kurang Setuju dan tidak ada, tidak setuju dan sangat tidak setuju. Dari data pada tabel 4.7 dapat disimpulkan bahwa responden setuju jika video promosi yang ditampilkan membuat responden tertarik beriklan di Batam TV.

c. Impact

Terdapat 1 butir pernyataan yang menjadi tolak ukur untuk dimensi impact pada penelitian ini yaitu :

\section{Butir Pertanyaan X5}

dapat diketahui bahwa sebanyak 62\%yang memilih sangat setuju, 38\% yang memilih setuju, dan tidak ada yang memilih kurang Setuju, tidak setuju dan sangat tidak setuju. Dari data pada tabel 4.8 dapat disimpulkan bahwa responden setuju jika video promosi yang ditampilkan memberikan pemahaman anda tentang harga pemasangan iklan di Batam TV.

\section{d. Communication}

Terdapat 1 butir pernyataan yang menjadi tolak ukur untuk dimensi communication pada penelitian ini yaitu :

\section{Butir Pertanyaan X6}

dapat diketahui bahwa sebanyak 66,6\% yang memilih sangat setuju, 33,3\% yang memilih setuju, dan tidak ada yang memilih kurang Setuju, tidak setuju dan sangat tidak setuju. Dari data pada tabel 4.9 dapat disimpulkan bahwa responden setuju jika video promosi yang ditampilkan menyampaikan pesan dengan jelas.

Tabel 6 Data Kuisoner

\begin{tabular}{|c|l|c|c|c|c|c|}
\hline \multirow{2}{*}{ Parameter } & $\begin{array}{c}\text { Perta } \\
\text { nyaa } \\
\mathrm{n}\end{array}$ & $\mathrm{SS}$ & $\mathrm{S}$ & $\begin{array}{c}\mathrm{K} \\
\mathrm{S}\end{array}$ & $\mathrm{TS}$ & $\begin{array}{c}\mathrm{ST} \\
\mathrm{S}\end{array}$ \\
\hline \multirow{2}{*}{ Emphaty } & $\mathrm{X} 1$ & 19 & 11 & 0 & 0 & 0 \\
\cline { 2 - 7 } & $\mathrm{X} 2$ & 14 & 15 & 1 & 0 & 0 \\
\hline Persuation & $\mathrm{X} 3$ & 14 & 16 & 0 & 0 & 0 \\
\cline { 2 - 8 } & $\mathrm{X} 4$ & 13 & 16 & 1 & 0 & 0 \\
\hline Impact & $\mathrm{X} 5$ & 18 & 12 & 0 & 0 & 0 \\
\hline Communication & $\mathrm{X} 6$ & 20 & 10 & 0 & 0 & 0 \\
\hline
\end{tabular}

Setelah di dapat data di atas, kemudian dilakukan penghitungan dengan Rumus skor rata- rata untuk mencari rata-rata per parameter dan menggunakan rumus EPIC rate untuk mencari nilai EPIC rata - rata.Lalu dilanjutkan untuk menghitung smua nilai dimensi, hasil penghitungan dan kriteria setiap dimensi dapat dilihat tabel 3.3

Tabel 7 Hasil perhitungan data kuisoner

\begin{tabular}{|c|c|l|}
\hline Parameter & Nilai & Kriteria \\
\hline Emphaty & 4,32 & Efektif \\
\hline Persuation & 4,27 & Efektif \\
\hline Impact & 4,6 & Efektif \\
\hline Communication & 4,66 & Efektif \\
\hline
\end{tabular}

Setelah semua nilai sudah didapatkan maka nilai dijumlah semua agar mengetahui nilai Epic Rate. Berikut perhitungan nilai Epic Rate: 


$$
\text { EPIC Rate }=\frac{4,32+4,27+4,6+4,66}{4}=4,46
$$

Hasil perhitungan untuk EPIC Rate didapatkan nilai sebesar 4,15. Pada rentan skala EPIC Model, 4,46 terletak di rentang nilai sangat efektif yaitu antara 4,21 - 5,00. Hal ini menandakan bahwa video promosi yang dibuat disukai oleh penonton, menarik perhatian, mampu membujuk dan meyakinkan penonton, memberi informasi tentang daftar harga pemasanga iklan di Batam TV.

\section{CONCLUSION (10 PT)}

Berdasarkan pengujian yang telah dilakukan maka diapat disimpulkan bahwa:

1.Video promosi rate card TVC Batam TV Motion Graphic dalam bentuk motion graphic dapat menjadi media dalam penyampaian informasi bagi masyarakat yang ingin beriklan di Batam TV berdasarkan hasil analisis yang telah dilakukan melalui kuisioner.

2.Dan hasil perhitungan kuisinoer sudah di dapat rata - rata dari semua aspek yaitu Emphaty dengan nilai 4,32, persuation dengan nilai 4,27, impact dengan nilai 4,6, communication dengan nilai 4,66, dan Epic Rate dengan nilai 4,46, hasil tersebut teletak di rentan skala sangat efektif yaitu antara 4,21 - 5,00 berdasarkan rentan skala pada EPIC model. Hal ini menandakan bahwa video promosi yang dibuat disukai oleh penonton,menarik perhatian, mampu membujuk dan meyakinkan penonton, memberi informasi tentang daftar harga pemasangan iklan di Batam TV.

\section{REFERENCES (10 PT)}

[1] Video Media Promosi Berbasis MotionS Graphic 2D Untuk Meningkatkan Jumlah Mahasiswa Universitas Widyagama Malang', JOINTECS Journal of Information Technology and Computer Science, 2(1), pp. 1-5. doi: 10.31328/jointecs.v2i1.417.

[2] Sufa, F. 2012 'Survei Pemirsa Iklan Mie Sedap Pada Mahasiswa Kost di sekitar'.

[3] Buku Batam TV 2005 . Batam.

[4] Ivan, M,. 2011. Pengertian Rate Card dan Bagaimana cara menentukannya.Jakarta.

[5] Choored, 2019. Pengertian Rate Card pada dunia advertasing. Jakarta. Pustaka Utama, 2003.

[6] Edy Widodo. 2017. Analisis Perbandingan Efektivitas Iklan Menggunakan EPIC

[7] Santoso, Handoko. 2017. Tinjauan Metode Pengembangan Perangkat Lunak Multimedia Yang Sesuai Untuk Mahasiswa Tugas Akhir.

[8] https://docplayer.info/50879193- Tinjauan-metode-pengembangan- perangkat-lunak-multimedia-yangsesuai-untuk-mahasiswa-tugas- akhir.html. [Diakses pada 20 October 2019] 